\title{
Erratum to: Development and validation of the biobanking attitudes and knowledge survey-Spanish (BANKS-SP)
}

\author{
Mariana Arevalo $^{1}$ Paul B. Jacobsen ${ }^{2,3}$. Clement K. Gwede . Cathy D. Meade $^{2,3}$. \\ Gwendolyn P. Quinn $^{2,3}$ • John S. Luque ${ }^{4}$. Gloria I. San Miguel ${ }^{5}$. Dale Watson ${ }^{6}$. \\ Kristen J. Wells ${ }^{7,8}$
}

Published online: 27 October 2016

(C) Springer-Verlag Berlin Heidelberg 2016

\section{Erratum to: J Community Genet}

DOI 10.1007/s12687-016-0280-6

The original version of this article unfortunately contained a mistake. One of the authors' was incorrectly captured. Instead of Gloria San Miguel it should have been Gloria I. San Miguel (Gloria as givenname, I as middle initial and San Miguel as familyname).

The online version of the original article can be found at http://dx.doi. org/10.1007/s12687-016-0280-6.

Kristen J. Wells

kwells@mail.sdsu.edu

1 University of Texas Health Science Center at Houston, Houston, TX, USA

2 Moffitt Cancer Center, Tampa, FL, USA

3 University of South Florida, Tampa, FL, USA

4 Medical University of South Carolina, Charleston, SC, USA

5 GuideWell Health, Largo, FL, USA

6 TBCCN Community Advisory Member, Tampa, FL, USA

7 Department of Psychology, San Diego State University, 6363 Alvarado Court, Suite 103, San Diego, CA 92120-1863, USA

8 Moores Cancer Center, San Diego, CA, USA 